\title{
Clear Cell Sarcoma of the Neck Which Metastasized to the Mammary Gland
}

\author{
Ippei Fukada $^{a}$ Seiichiro Nishimura $^{b}$ Masahiko Tanabe $^{b}$ \\ Hidetomo Morizono $^{b}$ Masujiro Makita ${ }^{b}$ Naoya Gomi ${ }^{c}$ Rie Horii ${ }^{d}$ \\ Futoshi Akiyama $^{\mathrm{e}}$ Takuji Iwase $^{\mathrm{b}}$ \\ ${ }^{a}$ Department of Breast Medical Oncology, ${ }^{b}$ Division of Breast Oncology, ${ }^{c}$ Department of \\ Diagnostic Imaging, and ${ }^{\mathrm{d}}$ Division of Pathology, the Cancer Institute Hospital of the \\ Japanese Foundation for Cancer Research, and ${ }^{\mathrm{e}}$ Division of Pathology, the Cancer \\ Institute of the Japanese Foundation for Cancer Research, Tokyo, Japan
}

\section{Key Words}

Breast cancer - Clear cell sarcoma - Metastasis to the mammary gland

\begin{abstract}
Malignant neoplasms very rarely metastasize to the mammary gland, the incidence of which is reported as $0.5-2 \%$. Clear cell sarcoma is a rare neoplasm, accounting for approximately $1 \%$ of all soft tissue tumors, which commonly occurs in the distal extremities of young adults aged approximately 20 to 40 years. So it is also called malignant melanoma of soft parts because it frequently produces melanin. We report a case of a 26 -year-old woman who presented with a neck mass. The mass was surgically removed, and pathological diagnosis was clear cell sarcoma of the neck, harboring the EWS-ATF1 chimeric gene. Computed tomography detected a right breast mass 11 months after operation. She was referred to our department, and the right breast tumor was resected. Histopathological examination revealed a $2.5-\mathrm{cm}$, well-defined mass composed of nests of small, spindle-shaped tumor cells with abundant, clear cytoplasm containing round nuclei and prominent nucleoli. The tumor cells were immunohistochemically positive for HMB45, S-100, and Melan-A. These findings led to a diagnosis of metastasis of clear cell sarcoma to the mammary gland. This is the first report of clear cell sarcoma of the neck which metastasized to the mammary gland.
\end{abstract}




\section{Introduction}

Clear cell sarcoma is a rare neoplasm, accounting for approximately $1 \%$ of all soft tissue tumors, which commonly occurs in the distal extremities of young adults aged approximately 20 to 40 years $[1,2]$ and is also called malignant melanoma of soft parts because it frequently produces melanin. We report a very rare case of primary clear cell sarcoma of the neck with recurrence in the mammary gland 11 months after surgery for primary lesion.

\section{Case Report}

The patient was a 26-year-old woman with a right breast mass. She had no family history of cancer. She underwent surgery for clear cell sarcoma of the neck at the age of 25 years. She noted a neck mass and visited a physician. She was diagnosed with malignant melanoma by cytological examination, so she visited the Department of Head and Neck Surgery of our hospital. MRI showed a $3.3 \times 3.5 \times 4.9$-cm lobulated mass involving the left vocal cord and upper pole and posterior aspect of the left thyroid lobe, suggestive of a clear cell sarcoma involving the left larynx, hypopharynx, and soft tissues of the neck. An incisional biopsy of the mass yielded a diagnosis of clear cell sarcoma of the neck, and she underwent total pharyngolaryngectomy, total thyroidectomy, regional lymph node dissection, and free jejunal reconstruction. Pathological examination led to a diagnosis of clear cell sarcoma (3.5 $\mathrm{cm}$ in diameter) of the neck arising in the soft tissue of the larynx and harboring the EWSATF1 chimeric gene. A follow-up CT scan 5 months after surgery showed no evidence of a breast mass, but a follow-up CT scan 11 months after surgery clearly demonstrated a right breast mass, and she was referred to our department for further evaluation and treatment.

In the CE area of the right breast, the tumor was freely movable, and the size was $3.5 \mathrm{~cm}$ in diameter. There were no palpable lymph nodes in the axilla or supraclavicular fossa. No nipple discharge was noted. A blood test was normal. Other laboratory data, including tumor markers, were within normal limits. Mammography revealed a polygonal, hyperdense mass with ill-defined margin near the right nipple. Mammography findings of the left breast were normal.

Breast ultrasound examination showed a $3.0 \times 2.8 \times 2.5-\mathrm{cm}$, well-defined, smoothsurfaced, hypo- to isoechoic mass in the mammary gland in the lateral portion of the right breast, along with a hypoechoic area with suspected central necrosis (fig. 1a). CE T1weighted MRI demonstrated a $3.2 \times 2.8 \times 2.7-\mathrm{cm}$ centrally necrotic mass with margins showing strong early enhancement (fig. 1b). These ultrasound and MRI findings suggested an invasive ductal carcinoma (solid tubular adenocarcinoma type) with central necrosis. FDG-PET revealed a round mass with FDG uptake (SUV: 8.7) in the right breast and a focus of FDG uptake (SUV: 4.5) adjacent to the right humerus (fig. 1c).

Fine-needle aspiration cytology of the breast mass showed numerous spindle-shaped or naked malignant cells with prominent nucleoli. Their cytoplasm was clear, and some cells contained melanin granules. Melanophages were observed in the surrounding tissue. These findings led to a diagnosis of clear cell sarcoma (fig. 2a). Fine-needle aspiration biopsy of the mass within the biceps brachii also yielded a diagnosis of clear cell sarcoma.

On the basis of the these findings, we diagnosed metastasis of the clear cell sarcoma to the mammary gland and biceps brachii from the neck, and performed resection of the right breast tumor and extensive resection of the biceps brachii. On macroscopic examination, the resected specimen comprised an approximately $3.0 \times 3.0-\mathrm{cm}$, well-defined, dark-brown, melanin-containing tumor in the mammary gland (fig. 2b). Histopathological examination 
revealed a 2.5-cm, well-defined mass composed of nests of small, spindle-shaped tumor cells with abundant, clear cytoplasm containing round nuclei and prominent nucleoli (fig. 3a). The tumor cells were immunohistochemically positive for HMB45, S-100, and Melan-A. These findings led to a diagnosis of metastasis of clear cell sarcoma to the mammary gland (fig. 3bd).

Five months after operation for the breast lesion, multiple metastases to the neck and the mediastinum lymph nodes were detected. The patient is under treatment with dacarbazine.

\section{Discussion}

Malignant neoplasms very rarely metastasize to the breast, the incidence of which is reported as $0.5-2 \%$ [3-6]. Such neoplasms reportedly include malignant lymphoma, malignant melanoma, lung cancer, and ovarian cancer [7].

Clear cell sarcoma was first reported by Enzinger et al. in 1965 [8]. On the basis of the immunohistochemical resemblance to malignant melanoma, in that it contains melanin granules and stains positive for the melanoma-associated antigen HMN-45, Chung and Enzinger [9] designated it as malignant melanoma of soft parts.

Studies have cytogenetically compared 2 histopathologically similar tumors: clear cell sarcoma and malignant melanoma. Zucman et al. [10] reported that clear cell sarcoma, but not malignant melanoma, was associated with the translocation $t(12 ; 22)(q 13 ; q 12)$ resulting in a chimeric $E W S / A T F 1$ gene. In addition, activating mutations in the kinase domain of the BRAF gene were only detected in malignant melanoma [11]. These findings demonstrate a difference between malignant melanoma and clear cell sarcoma.

Clear cell sarcoma is a high-grade sarcoma with morphological features resembling those of malignant melanoma [1]. It commonly arises in the tendons and aponeuroses of young adults [2] and is a rare neoplasm, accounting for approximately $1 \%$ of all soft tissue tumors. Clear cell sarcoma has been reported to be clinicopathologically characterized by its predilection for occurrence in the extremities of relatively young adults and by its slow growth. However, the prognosis of patients with clear cell sarcoma is poor because of frequent distant metastasis. Lucas et al. [12] reported 5- and 10-year survival rates of 67 and $33 \%$, respectively. Kawai et al. [13] reported that the tumor diameter was the most important prognostic factor in clear cell sarcoma, with a distant metastasis rate of $79 \%$ for tumors of $5 \mathrm{~cm}$ or more and $48 \%$ for those of less than $5 \mathrm{~cm}$ in diameter. Clear cell sarcoma can be treated with chemotherapy such as doxorubicin-based regimen and dacarbazine, and Kawai et al. [13] reported a response rate of $23 \%$ in chemotherapy-treated patients; however, in general, chemotherapy has limited effectiveness.

Metastasis of sarcoma to the breast is extremely rare. In Japan, $9(0.1 \%)$ of 1,592 patients with sarcomas (excluding malignant lymphoma) were reported to have mammary gland metastasis, but the details are unknown [14]. There were no reports of the mammary gland metastasis of clear cell sarcoma.

In this case, fine-needle aspiration biopsy from the masses in the breast and the biceps brachii led to a diagnosis of clear cell sarcoma with metastasis to the mammary glands and biceps brachii. Although surgery was expected to be of limited efficacy in this case, we performed resection of the right breast tumor and extensive resection of the biceps brachii, because the metastatic lesions were relatively localized, metastatic lesions in the mammary gland tend to increase in size, and the patient was young and strongly desired surgery. 
Fukada et al.: Clear Cell Sarcoma of the Neck Which Metastasized to the Mammary Gland

\section{Conclusion}

This is the first report of clear cell sarcoma of the neck which metastasized to the mammary gland. When breast tumor is seen in patients with a past history of malignant disease, it is necessary to suspect the possibility of breast metastasis. In patients with distant metastasis of malignant neoplasm, the disease progresses rapidly, and multiple metastases are often found at the time of diagnosis, indicating a poor prognosis. Therefore, surgery for metastatic lesions should be considered only if the primary lesion is well controlled and the metastases are localized. It is important to avoid unnecessary radical surgery and to perform appropriate systemic therapy.

\section{Disclosure Statement}

The authors declare that they have no conflict of interest.

\section{References}

1 Panagopoulos I, Mertens F, Debiec-Rychter M, Isaksson M, Limon J, Kardas I, et al: Molecular genetic characterization of EWS/AFT1 fusion gene in clear cell sarcoma of tendons and aponeuroses. Int J Cancer 2002;99:560-567.

-2 Pauwels P, Debiec-Rychter M, Sciot R, Vlasveld T, den Butter B, Hagemeijer A, et al: Clear cell sarcoma of the stomach. Histopathology 2002;41:526-530.

-3 Abrams HL, Spiro R, Goldstein N: Metastases in carcinoma: analysis of 1,000 autopsied cases. Cancer 1950;3:74-85.

4 Sandison AT: Metastatic tumors in the breast. Br J Surg 1959;47:54-58.

-5 Hajdu SI, Urban JA: Cancers metastatic to the breast. Cancer 1972;29:1691-1696.

-6 Vergier B, Trojani M, De Mascarel I, Coindre J, Treut A: Metastasis to the breast: differential diagnosis from primary breast carcinoma. J Surg Oncol 1991;48:112-116.

7 Vizcaino I, Torregrosa A, Higueras V, Morote V, Cremades A, Torres V, et al: Metastasis to the breast from extramammary malignancies: a report of four cases and a review of literature. Eur Radiol 2001;11:16591665.

8 Enzinger FM: Clear-cell sarcoma of tendons and aponeuroses: an analysis of 21 cases. Cancer $1965 ; 18: 1163-1174$.

$\$ 9$ Chung EB, Enzinger FM: Malignant melanoma of soft parts: a reassessment of clear cell sarcoma. Am J Surg Pathol 1983;7:405-413.

10 Zucman J, Delattre O, Desmaze C, Epstein AL, Stenman G, Speleman F, et al: EWS and ATF-1 gene fusion induced by $\mathrm{t}(12 ; 22)$ translocation in malignant melanoma of soft parts. Nat Genet 1993;4:341-345.

11 Katabuchi H, Honda R, Tajima T, Ohtake H, Kageshita T, Ono T, et al: Clear cell sarcoma arising in the retroperitoneum. Int J Gynecol Cancer 2002;12:124-127.

12 Lucas DR, Nascimento AG, Sim FH: Clear cell sarcoma of soft tissues: Mayo clinic experience with 35 cases. Am J Surg Pathol 1992;16:1197-1204.

13 Kawai A, Hosono A, Nakayama R, Matsumine A, Matsumoto S, Ueda T, et al: Clear cell sarcoma of tendons and aponeuroses: a study of 75 cases. Cancer 2007;109:109-116.

14 Urano Y, Fukushima T, Kitamura S, Mori H, Baba K, Aizawa S: Metastasis to the mammary gland, metastasis from the mammary gland. Jpn J Cancer Clinics (Suppl) Clinics of Breast Cancer II. Shinoharashinsha Inc., Tokyo, 1986, pp 205-223. 

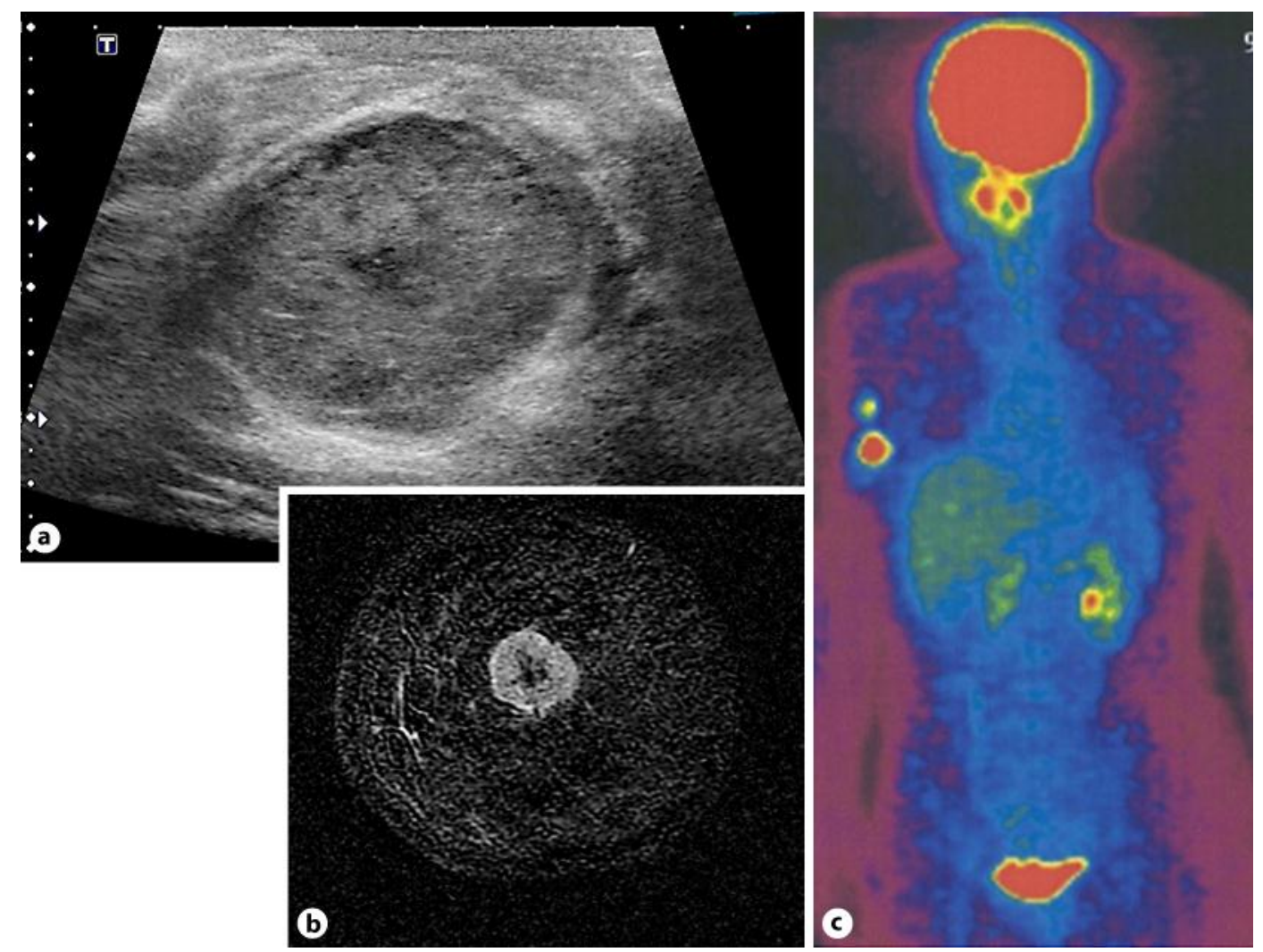

Fig. 1. a Breast ultrasound examination. A well-defined, smooth-surfaced, hypo- to isoechoic mass in the mammary gland, along with a hypoechoic area with suspected central necrosis. b Breast MRI. On CET1weighted MRI, a centrally necrotic mass with margins showing strong early enhancement was noted (60 s). c MIP PET/CT. A round mass with FDG uptake (SUV: 8.7) was observed in the right breast, along with a focus of FDG uptake (SUV: 4.5) adjacent to the right humerus. 


\section{Case Reports in Oncology}

\begin{tabular}{|c|c|}
\hline \multicolumn{2}{|c|}{ Case Rep Oncol 2013;6:55-61 } \\
\hline DOI: $\underline{10.1159 / 000345843}$ & $\begin{array}{l}\text { (c) } 2013 \text { S. Karger AG, Basel } \\
\text { www.karger.com/cro }\end{array}$ \\
\hline
\end{tabular}
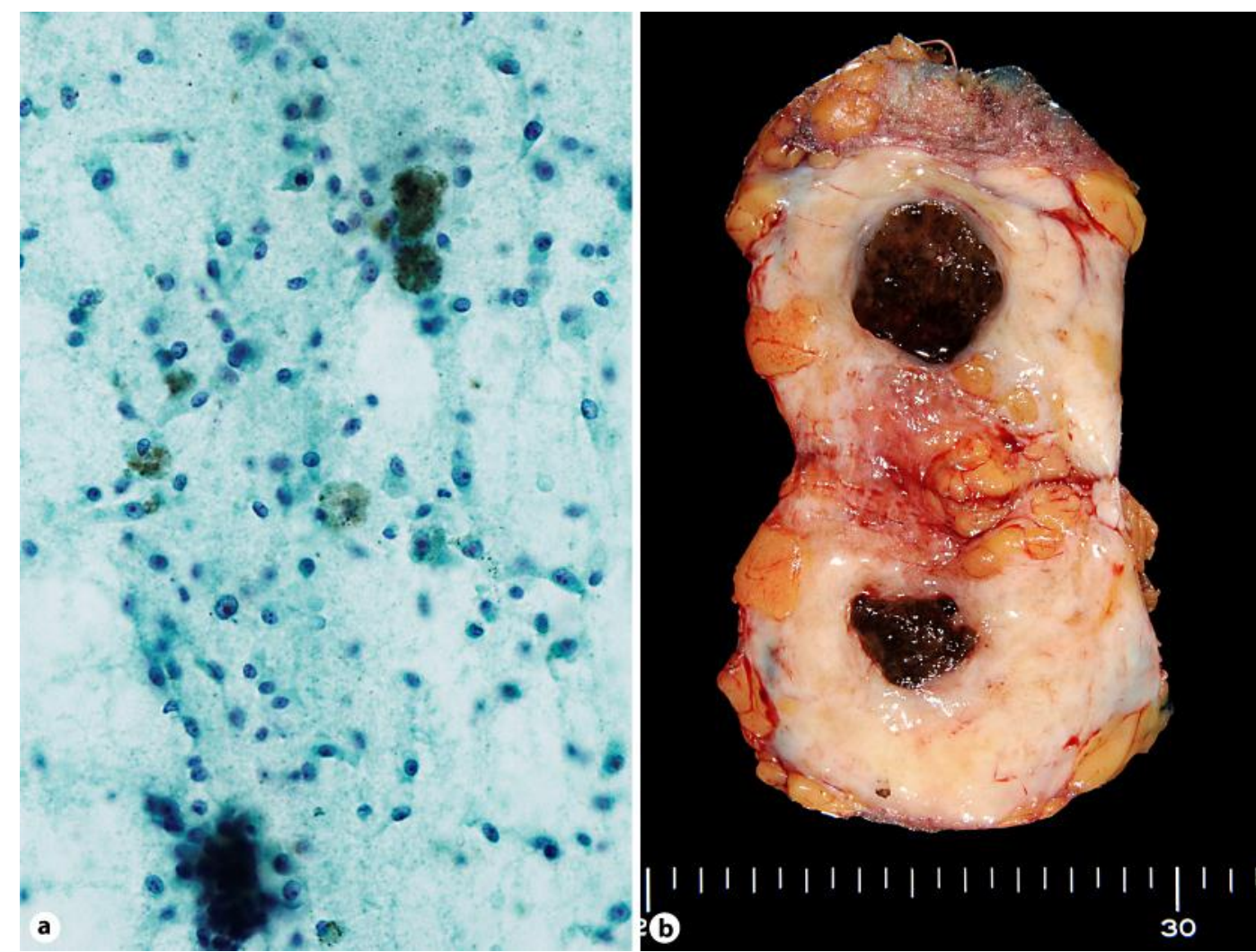

Fig. 2. a Fine-needle aspiration biopsy cytology of the breast mass. Numerous spindle-shaped or naked malignant cells with prominent nucleoli were seen. Their cytoplasm was clear, and some cells contained melanin granules. Melanophages were also present. b Gross findings of the resected specimen. An approximately $3.0 \times 3.0-\mathrm{cm}$, well-defined, dark-brown, melanin-containing tumor was observed in the mammary gland. 


\section{Case Reports in Oncology}

\begin{tabular}{l|l}
\hline Case Rep Oncol 2013;6:55-61 \\
\hline DOI: $\underline{10.1159 / 000345843}$ & $\begin{array}{l}\text { C 2013 S. Karger AG, Basel } \\
\text { www.karger.com/cro }\end{array}$ \\
\hline
\end{tabular}

Fukada et al.: Clear Cell Sarcoma of the Neck Which Metastasized to the Mammary Gland
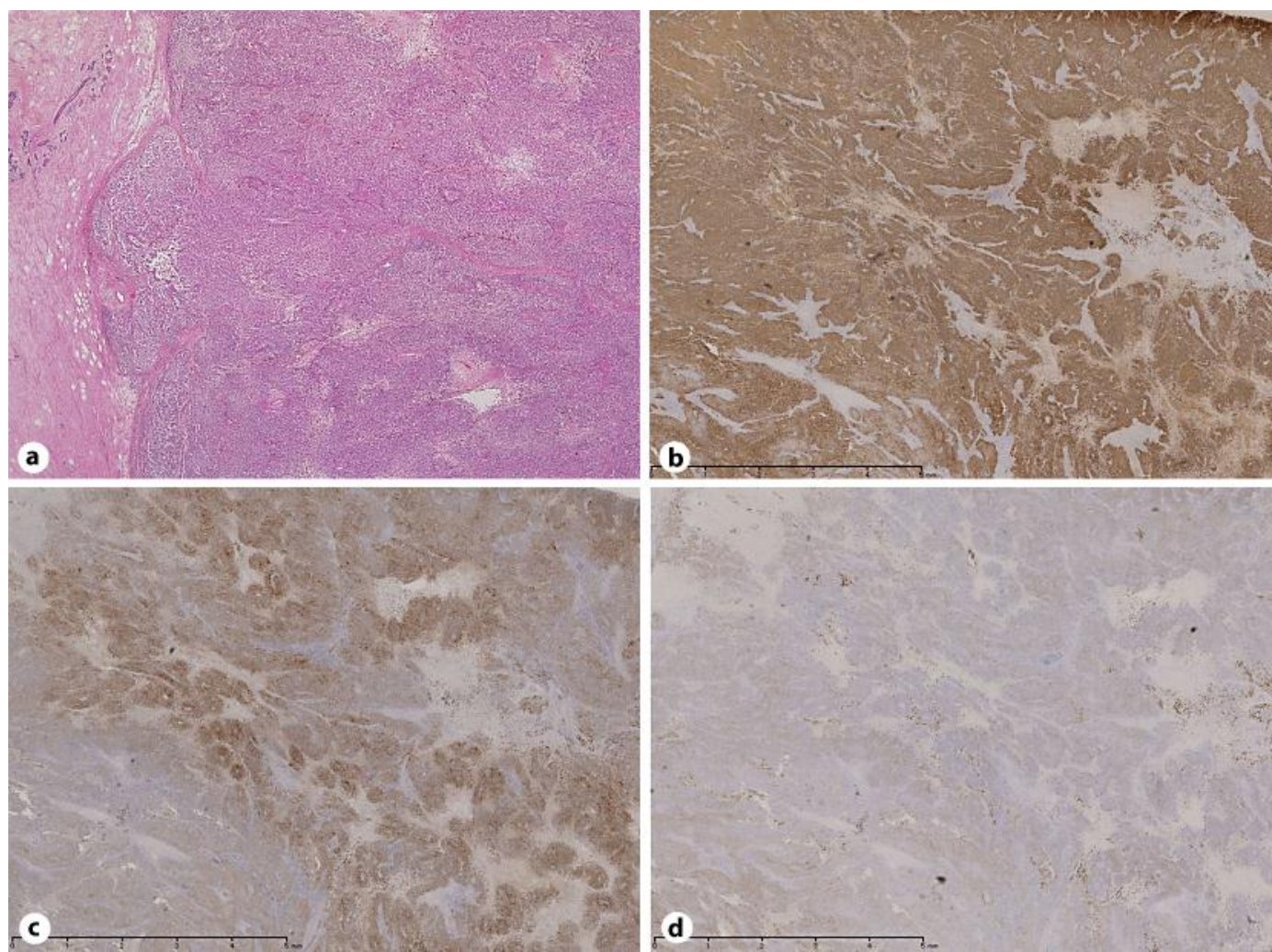

Fig. 3. Histopathological findings. A well-defined solid mass comprising nests of small, spindle-shaped, melanin-containing cells was observed (a). The tumor cells were immunohistochemically positive for HMB45 (b), S-100 (c), and Melan-A (d). 